\title{
A summary overview of the new, direct, target-specific oral anticoagulants
}

\section{GL Muntingh}

Department of Pharmacology, School of Medicine, Faculty of Health Sciences, University of Pretoria

Corresponding author, email: George.muntingh@up.ac.za

\begin{abstract}
In the past 10 years or so, many alternatives to warfarin have been developed the first being the novel oral anticoagulants (NOAC) or better referred to as direct oral anticoagulants (DOAC) or target-specific oral anticoagulants (TSOAC). These drugs have some definite advantages and disadvantages that should be clear to physicians before prescribing any of them for patients. Many clinical trials have provided definitive information about the efficacy and safety of DOACs, yet many physicians remain sceptical about prescribing these drugs due to lack of answers to real world questions. The concerns are directed towards appropriate patient selection (the choice should be made according to age, renal function, compliance, cost, clinical condition, intake of other drugs), the mechanism of switching between agents, how these drugs affect routine laboratory tests and when monitoring is needed. Knowledge of other drugs that interact with the DOAC and management of severe bleeding will be reviewed and recommendations will be given to all of these concerns.
\end{abstract}

Keywords: oral anticoagulants, target-specific, mechanism, clinical, pharmacokinetics

\section{Introduction}

"The human body contains blood, phlegm, yellow bile and black bile. These are the things that make up its constitution and cause its pain and health. Health is primarily that state in which these constituent substances are in the correct proportion to each other, both in strength and quantity, and are well mixed." Hippocrates'

Blood has been considered sacred since ancient times and this is recognised by the Chinese character for a blood clot which originates from the hieroglyphical symbol of "a sacrifice placed in a vessel".2 (Figure 1.)

For over 50 years, warfarin was the only anticoagulant available in oral form, but now the availability of direct oral anticoagulants (DOACs) has caused a paradigm shift in thrombosis management.

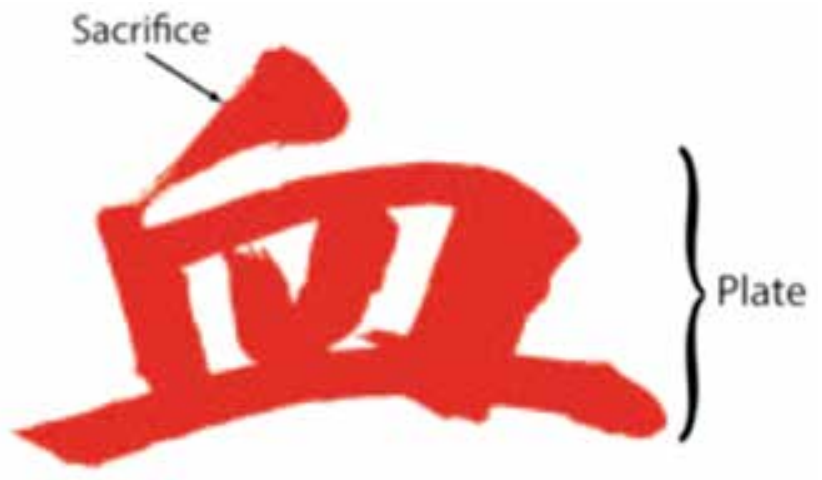

Figure 1. A diagonal stroke over the symbol of the plate signifies "the sacrifice placed on the plate"
The historical standard of care for venous thrombotic events (VTE) treatment is initiated by the administration of a parenteral anticoagulant for five days or so, followed by overlapping treatment with a vitamin $\mathrm{K}$ antagonist (VKA) e.g. warfarin. The parenteral anticoagulant options for VTE treatment include intravenous unfractionated heparin, subcutaneous low-molecular-weight heparin (LMWH) (e.g. enoxaparin), or fondaparinux. Although heparins are safe and effective agents for the rapid initiation of treatment in acute thrombotic events and VKAs are reliable and inexpensive treatment options when long-term anticoagulation treatment is indicated, there are several limitations to their use despite their extensive efficacy. Warfarin interacts with a multitude of drugs and foods, has a delayed onset of action, has a narrow therapeutic range, requires routine therapeutic monitoring, and exhibits variability in patient response as influenced by genetic factors. Limitations of unfractionated heparin and low molecular weight heparins include hospitalisation, haemorrhagic complications, frequent monitoring and adjustment of dosing, and the potential development of heparin-induced thrombocytopaenia. ${ }^{3}$ The need for new orally administered anticoagulants with improved characteristics is essential.

The first oral anticoagulant competitors to warfarin are the novel oral anticoagulants, better referred to as direct oral anticoagulants (DOAC) or target-specific oral anticoagulants (TSOAC): dabigatran (Pradaxa ${ }^{\circledR}$ ) became the first alternative to VKA as a direct thrombin inhibitor in 2010, ${ }^{4}$ rivaroxaban (Xarelto ${ }^{\oplus}$ ) 


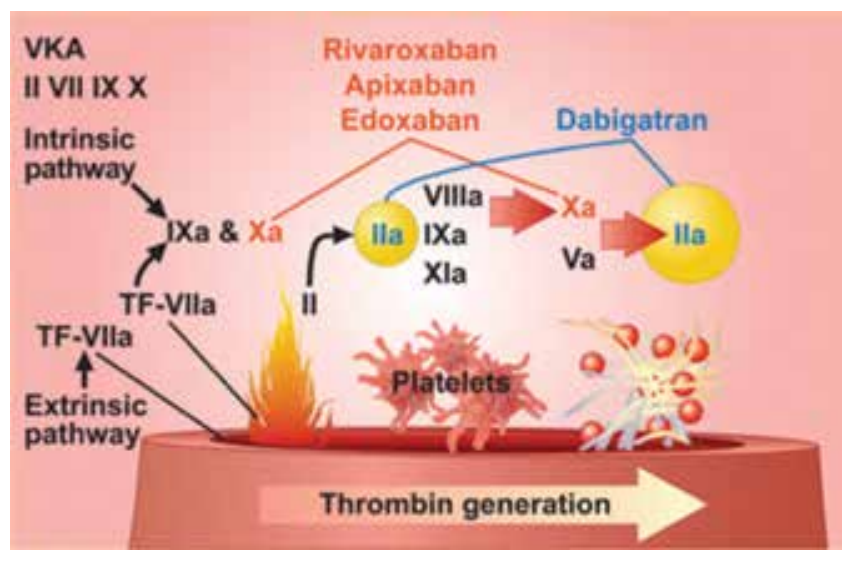

Figure 2. Coagulation process and targets of direct oral anticoagulants (DOACs). Contrary to DOACs, vitamin-K antagonists (VKA) have multiple targets (including factors II, VII, IX and X).

became the first available factor Xa inhibitor, ${ }^{5}$ followed by apixaban (Eliquis ${ }^{\oplus}$ ) in 2012, ${ }^{6}$ and edoxaban in 2015. ${ }^{7}$ (Figure 2.)

The DOACs have definite advantages and disadvantages that should be clear to physicians before prescribing any of them for patients.

\section{Advantages of direct oral anticoagulants}

Despite the convenience of oral administration, the use of warfarin is complicated by delayed onset of action, narrow target therapeutic range, unpredictable dose responses, and numerous food and drug interactions. Patients taking warfarin also require frequent monitoring, as variable levels of anticoagulation increase the risk for both recurrent thromboembolism and bleeding.

Some advantages of the DOACs include quick onset/offset of action (short half-lives). This allows for no required bridging with injectable anticoagulants since time from dosing to therapeutic effectiveness is short. It also allows for easy perioperative or procedure management. They have predictable kinetics and small inter-individual variation which supports use of fixed dosing regimens that are the same for all patients. No routine laboratory monitoring is needed. Medications are efficacious and relatively safe, proven to be at least non-inferior to warfarin and have similar/improved bleeding rates in trials. ${ }^{8}$ Both dabigatrin and rivaroxaban have shown reductions in intracranial haemorrhage compared to warfarin.

\section{Limitations of the direct oral anticoagulant in}

\section{comparison to warfarin}

There are several limitations to DOAC use: They are more expensive. There is no antidote for easy reversibility in the management of bleeds or when urgent surgery is needed. There is a lack of accurate monitoring in suspected toxicity cases. They need to be dose adjusted for renal dysfunction (and require renal monitoring) so cannot be used in patients with moderate-severe renal impairment or prosthetic heart valves. In addition, there are some adherence concerns. Due to the short half-life of the new drugs, a missed dose can place a patient at increased risk of an adverse event or under anticoagulation. Furthermore, those DOACs with twice-daily dosing regimens may negatively impact compliance. ${ }^{8}$

Warfarin and the new oral anticoagulants differ in their pharmacokinetic properties. While the DOACs all have a quick onset of action with an effect within 2-3 $\mathrm{h}$ and similar half-lives of approximately 12 hours, their bioavailability, metabolism, and clearance are different. (Table I.) ${ }^{9}$

\section{Dabigatran}

Dabigatran is indicated for the (1) prevention of stroke and systemic embolism in patients with non-valvular atrial fibrillation (AF), (2) prevention of venous thromboembolic events (VTE) in patients who have undergone elective total hip replacement or total knee replacement surgery, (3) treatment/prevention of deep vein thrombosis and pulmonary embolism. ${ }^{4}$

Dosing differs for each indication and dosage adjustment is required for patients with moderate renal impairment and those considered at higher risk of bleeds (active peptic ulcer disease, on anti-platelets or interacting medication). Patients can also experience many gastrointestinal tract (GIT) issues, the most common being reflux of acid. About $10 \%$ of patients on dabigatran complain of symptoms of dyspepsia. It may be taken with food to minimise GIT upset but if the symptoms are intolerable, patients should be reassessed and switched to other oral anticoagulant options.

Since the DOACs have a reasonably fast onset and offset, missing a dose puts the patient at risk of events due to under anticoagulation.

Important information for the patient: Dabigatran needs to be swallowed whole; it cannot be crushed, chewed, or the capsule opened. It cannot be sprinkled as pellets in food or mixed in liquids. The bioavailability may be increased by $75 \%$ if the capsules are opened and this could dramatically increase blood drug levels and the risk of bleeding.

Table I. Summary of the pharmacokinetics of warfarin, dabigatrin and rivaroxaban

\begin{tabular}{|c|c|c|c|}
\hline Factor & Warfarin & Dabigatrin & Rivaroxaban \\
\hline Bioavailability & $\sim 100 \%$ & $3-7 \%$ & $\begin{array}{l}10 \mathrm{mg} \text { Dose: } 80-100 \% \\
20 \mathrm{mg} \text { dose: } 66 \%\end{array}$ \\
\hline Time to $\mathrm{Cmax}$ & $4 \mathrm{~h}$ & $1-2 \mathrm{~h}$ & $3-4 h$ \\
\hline Plasma protein binding & $\approx 99 \%$ & $\approx 35 \%$ & $92-95 \%$ \\
\hline Metabolism & CYP2C9, 2C8, 2C18, 1A2, 3A4 & Conjugation, prodrug is Pgp substrate & CYP3A4, 1A2, 2C8, 2C19, Pgp substrate \\
\hline Elimination & Hepatic metabolsim & Renal $80 \%$ & Renal $66 \%, 36 \%$ unchanged \\
\hline Half-life & $\approx 40 \mathrm{~h}$ & $12-17 \mathrm{~h}$ & 5-9 h, longer in elderly \\
\hline
\end{tabular}




\section{Rivaroxaban}

Rivaroxaban has the same indications as dabigatran. It is available as $10 \mathrm{mg}, 15 \mathrm{mg}$, and $20 \mathrm{mg}$ tablets and only requires a dosage adjustment for AF stroke prevention in patients with moderate renal dysfunction. ${ }^{3}$

Special patient Information: it is recommended to take rivaroxaban with food in order to increase absorption, and crushing the tablet, and mixing with applesauce helps in oral administration. It can also be crushed and suspended in water $(50 \mathrm{~mL})$ and administered via a nasogastric tube within four hours of mixing.

Rivaroxaban also has specific instructions for managing missed doses; these directions differ depending on the indication and dosing regimen.

\section{Patient selection}

Choice of drug should be made according to age, renal function, compliance, cost, clinical condition, and intake of other drugs. Some patients will have many of these characteristics and it therefore necessitates clinical judgment in guiding the choice of drugs. ${ }^{10}$

Age - for younger patients with good kidney function - DOAC is preferred. When patients get to 75 or 80 years old, it is likely DOAC is still the preferred agent but lower doses may need to be used.

For any compromised renal dysfunction or creatinine clearance $(\mathrm{CrCl})<50 \mathrm{~mL} / \mathrm{min}$, warfarin is the safest as it is mainly eliminated through the liver. For moderate renal dysfunction defined as $\mathrm{CrCl}$ $30-50 \mathrm{~mL} / \mathrm{min}$, lower doses of the DOACs are an option.

If time in therapeutic range (TTR) is $>65 \%$, the patient is already stable on warfarin and has no bleeding, one might as well continue therapy. If the patient has a history of poor international normalised ratio (INR) control, despite good compliance with warfarin as indicated by TTR $<65 \%$, DOAC may be a better option.

If the patient has a compliance issue, none of the drugs are preferred as the patient is likely not regularly taking any of them. Warfarin is preferred since it can be monitored by INR. This is not possible with the DOACs.

DOAC is contraindicated in severe liver and/or renal disease, mechanical heart valves, rheumatic heart disease, valvular $\mathrm{AF}$, recent major bleeding, acute stroke or systemic embolism, pregnancy or breastfeeding, and interacting medications.

The ideal candidate for DOAC is the newly diagnosed nonvalvular AF since the DOACs work as well or maybe even better than warfarin, depending on the drug and dosage.

Patients with recent coronary artery disease or those that have had angioplasty and are required to take dual antiplatelet therapy with drugs such as acetylsalicylic acid, clopidogrel, prasugrel or ticagrelor - should be on warfarin if they require an oral anticoagulant. There is not much experience or trial information on the use of DOACs in this patient population. Dabigatran has also shown a possible trend for increased myocardial infarctions. Patients that do want to use warfarin may be able to use a DOAC later on, either after time from their coronary event has elapsed or when they are not taking multiple antiplatelets/anticoagulants together.

Dabigatran and rivaroxaban have trial evidence of more gastrointestinal bleeds, so these patients should preferably be on warfarin.

Patients with dyspepsia should not be on dabigatran as this is its most common side-effect. The other DOACs are good choices.

Any patient who has had issues with past warfarin use such as therapy failure, side-effects, allergy, or barriers to laboratory monitoring should be on a DOAC.

Patients with a high bleeding risk should have warfarin as the agent of preference. Apixaban may be an option since it seems to have fewer bleeds when compared to other DOACs.

\section{Switching between agents}

Patients on many occasions will switch between anticoagulants for a variety of reasons in a variety of settings, switching from warfarin to DOAC or from DOAC to warfarin or between DOACs. [Table II.] ${ }^{11}$

Table II. Switching between DOACs and warfarin

\begin{tabular}{|c|c|c|}
\hline From & To & How to switch \\
\hline Warfarin & DOAC & $\begin{array}{l}\text { Stop warfarin and start dabigatran when } \\
\text { INR }<2 \\
\text { Stop warfarin and start rivaroxaban when } \\
\text { INR }<2.5\end{array}$ \\
\hline Dabigatran & Warfarin & $\begin{array}{l}\mathrm{CrCL}>50 \mathrm{~mL} / \mathrm{min} \text { : start warfarin } 3 \text { days } \\
\text { before stopping dabigatran } \\
\mathrm{CrCL} 31-50 \mathrm{~mL} / \mathrm{min} \text { : start warfarin } 2 \text { days } \\
\text { before stopping dabigatran } \\
\mathrm{CrCL} 15-30 \mathrm{~mL} / \mathrm{min} \text { : start warfarin } 1 \text { day } \\
\text { before stopping dabigatran } \\
\mathrm{CrCL}<15 \mathrm{~mL} / \mathrm{min} \text { : no recommendations } \\
\text { provided }\end{array}$ \\
\hline Rivaroxaban & Warfarin & $\begin{array}{l}\text { Start warfarin with rivaroxaban until INR } \geq \\
2.0 \text { and then stop rivaroxaban } \\
\text { (INR should be determined just before } \\
\text { rivaroxaban dose) }\end{array}$ \\
\hline
\end{tabular}

\section{Peri-procedural management}

There are situations in which patients may need to interrupt their oral anticoagulant therapy for any surgical procedure, or major dental work. The duration of holding the drug depends on the type of procedure or surgery, its bleeding risk, and the patient's renal function. ${ }^{12}$ There is no drug administration the day of surgery. If a patient has good kidney function and is undergoing a major procedure (cardiac surgery, neurosurgery, major cancer), he/she should not take the drugs for a full two days. If the same patient is going for a low bleeding risk procedure, he/she should not take the drugs for one full day. If a patient has reduced renal function, he/she should hold medication for longer.

Resuming therapy: It is important that patients are aware that they need to resume their oral anticoagulant therapy postprocedure or surgery. Usually, resumption of therapy occurs when adequate haemostasis has been achieved or the clinical 
Table III. Drug-drug interactions

\begin{tabular}{|c|c|c|c|}
\hline Interaction type & Effect & Dabigatran & Rivaroxaban \\
\hline \multirow[t]{2}{*}{ Pharmacokinetic } & $\begin{array}{l}50 \% \text { increase in anticoagulant } \\
\text { plasma concentration }\end{array}$ & $\begin{array}{l}\text { Verapamil } \\
\text { Quinidine } \\
\text { Ketoconazole } \\
\text { Amiodarone }\end{array}$ & $\begin{array}{l}\text { Clarithromycin } \\
\text { Itraconazole } \\
\text { Ketocanozole } \\
\text { Ritonavir } \\
\text { Voriconazole }\end{array}$ \\
\hline & $\begin{array}{l}50 \% \text { decrease in anticoagulant } \\
\text { plasma concentration }\end{array}$ & $\begin{array}{l}\text { Carbamazepine } \\
\text { Rifampicin } \\
\text { St Johns wort }\end{array}$ & $\begin{array}{l}\text { Carbamazepine } \\
\text { Rifampicin } \\
\text { St Johns wort } \\
\text { Phenytoin } \\
\text { Phenobarbital }\end{array}$ \\
\hline Pharmacodynamic & Increased risk of bleeding & $\begin{array}{l}\text { ASA } \\
\text { NSAIDs } \\
\text { Platelet inhibitors } \\
\text { Thrombolytics }\end{array}$ & $\begin{array}{l}\text { ASA } \\
\text { NSAIDs } \\
\text { Platelet inhibitors } \\
\text { Thrombolytics }\end{array}$ \\
\hline
\end{tabular}

situation allows. ${ }^{13}$ This is usually 24 hours postoperatively for a low bleeding risk surgery and 48 hours for a high bleeding risk surgery. For patients at high risk of thromboembolism, consider administering a reduced dose of the oral anticoagulant on the evening after surgery and on the first postoperative day for high bleeding risk surgeries. This needs to be decided on an individual basis.

\section{Interaction with other drugs and diet}

Although one of the advantages of the DOAC over warfarin is the minimal interaction of drugs, there are many pharmacodynamic and pharmacokinetic effects with other medications which can lead to increasing or decreasing the effect of the drug. (Table III.) $)^{14}$

\section{Management of bleeding}

The lack of an effective antidote and lack of definitive information about how best to manage patients with DOAC-associated lifethreatening bleeding probably leads many physicians to avoid prescribing DOACs. There are no evidence-based guidelines on how to manage major bleeding. Oral activated charcoal, red cell transfusion, haemodialysis, fresh frozen plasma, and activated Factor VII have all been tried empirically.

The issue of bleeding is perhaps exaggerated. The half-life of the drug is short and during the RE-LY trial, during which 399 patients taking dabigatran $150 \mathrm{mg}$ twice-daily experienced a major haemorrhage, only two $(0.5 \%)$ and seven $(1.8 \%)$ received either PCC or rFVIla, respectively.

There is indirect evidence that, in the majority of nearly 400 cases of dabigatran-related major bleeding, the treating physician saw no need to escalate beyond supportive care such as red blood cell transfusion. ${ }^{15}$

Recently antidotes to dabigatran and rivaroxaban were launched, namely idarucizumab and andexanet alfa respectively. This will definitely encourage more use of these drugs by physicians. ${ }^{16}$

\section{Conclusion}

DOACs exhibit the advantages of fixed-dose oral dosing, relatively rapid onset and offset, and fewer drug-drug interactions compared with warfarin. DOACs have become viable alternatives to conventional oral anticoagulants.
Common errors related to DOAC use have been recognised and include prescribing to inappropriate patients, recommending an inappropriate dose or administration, and inappropriate monitoring. Optimal use of DOACs requires familiarity with pharmacokinetic/pharmacodynamic profiles, various dosing strategies, laboratory monitoring, peri-procedural and switching strategies, and general approaches to bleeding management.

\section{References}

1. http://www.azquotes.com/quote/989568. Accessed 31 May 2016.

2. Tenaka KA, Key NS, Levy JH. Blood Coagulation: Hemostasis and Thrombin Regulation. Anesthesia and Analgesia. 06/2009; 108(5):1433-46.

3. Galanis T, Keiffer G, Merli G. The new oral anticoagulants for the treatment of venous thromboembolism: A new paradigm shift in antithrombotic therapy. Curr Ther Res Clin Exp 2014;76:76-83.

4. Schulman S, Kearon C, Kakkar AK, et al. Extended use of dabigatran, warfarin, or placebo in venous thromboembolism. N Engl J Med 2013;368:709-18.

5. Patel MR, Mahaffey KW, Garg J, et al. Rivaroxaban versus warfarin in nonvalvular atrial fibrillation. N Engl J Med 2011;365:883-91.

6. Connolly SJ, Eikelboom J, Joyner C, et al. Apixaban in patients with atrial fibrillation. N Engl J Med 2011;364:806-17.

7. Büller $H R$, Décousus $H$, Grosso $M A$, et al. Edoxaban versus warfarin for the treatment of symptomatic venous thromboembolism. N Engl J Med 2013;369:1406-15.

8. Lega JC, Bertoletti L, Gremillet C, et al. Consistency of safety profile of new oral anticoagulants in patients with renal failure. J Thromb Haemost 2014;12:337-43.

9. Husted $S$, de Caterina $R$, Andreotti $F$, et al. Non-Vitamin $K$ antagonist oral anticoagulants (NOACs): No longer new or novel. Thromb Haemost 2014;111:781-2.

10. January CT, Wann LS, Alpert JS, et al. 2014 AHA/ACC/HRS guideline for the management of patients with atrial fibrillation: A report of the American College of Cardiology/American Heart Association Task Force on Practice Guidelines and the Heart Rhythm Society. J Am Coll Cardiol 2014;64:e1-76.

11. Schulman S, Crowther MA. How I treat with anticoagulants in 2012: New and old anticoagulants, and when and how to switch. Blood 2012;119:3016-23.

12. Douketis JD, Spyropoulos AC, Kaatz $S$, et al. Perioperative bridging anticoagulation in patients with atrial fibrillation. N Engl J Med 2015;373:823-33.

13. Healey JS, Eikelboom J, Douketis J, et al. Periprocedural bleeding and thromboembolic events with dabigatran compared with warfarin: Results from the randomized evaluation of long-term anticoagulation therapy (RE-LY) randomized trial. Circulation 2012;126:343-8.

14. Frost $C$, Nepal $S$, Wang J, et al. Safety, pharmacokinetics and pharmacodynamics of multiple oral doses of apixaban, a factor Xa inhibitor, in healthy subjects. $\mathrm{Br} \mathrm{J}$ Clin Pharmacol 2013;76:776-86.

15. Siegal DM, Garcia DA, Crowther MA. How I treat target-specific oral anticoagulant-associated bleeding. Blood 2014;123:1152-8.

16. Pollack CV Jr, Reilly PA, Eikelboom J, et al. Idarucizumab for dabigatran reversal. N Engl J Med 2015;373:511-20. 